\title{
a7 Nicotinic acetylcholine receptors and temporal memory: Synergistic effects of combining prenatal choline and nicotine on reinforcement-induced resetting of an interval clock
}

\author{
Ruey-Kuang Cheng, Warren H. Meck, ${ }^{1}$ and Christina L. Williams \\ Department of Psychological and Brain Sciences, Duke University, Durham, North Carolina 27708, USA
}

\begin{abstract}
We previously showed that prenatal choline supplementation could increase the precision of timing and temporal memory and facilitate simultaneous temporal processing in mature and aged rats. In the present study, we investigated the ability of adult rats to selectively control the reinforcement-induced resetting of an internal clock as a function of prenatal drug treatments designed to affect the $\alpha 7$ nicotinic acetylcholine receptor $(\boldsymbol{\alpha} 7 \mathrm{nAChR})$. Male Sprague-Dawley rats were exposed to prenatal choline (CHO), nicotine (NIC), methyllycaconitine (MLA), choline + nicotine $(\mathrm{CHO}+\mathrm{NIC})$, choline + nicotine + methyllycaconitine $(\mathrm{CHO}+\mathrm{NIC}+\mathrm{MLA})$, or a control treatment (CON). Beginning at 4-mo-of-age, rats were trained on a peak-interval timing procedure in which food was available at 10-, 30-, and 90-sec criterion durations. At steady-state performance there were no differences in timing accuracy, precision, or resetting among the CON, MLA, and CHO + NIC + MLA treatments. It was observed that the CHO and NIC treatments produced a small, but significant increase in timing precision, but no change in accuracy or resetting. In contrast, the $\mathrm{CHO}+\mathrm{NIC}$ prenatal treatment produced a dramatic increase in timing precision and selective control of the resetting mechanism with no change in overall timing accuracy. The synergistic effect of combining prenatal $\mathrm{CHO}$ and $\mathrm{NIC}$ treatments suggests an organizational change in $\boldsymbol{\alpha} 7 \mathrm{nAChR}$ function that is dependent upon a combination of selective and nonselective $\mathrm{AAChR}$ stimulation during early development.
\end{abstract}

The cognitive processes involved in duration discrimination are generally thought to include attention, clock, memory, and decision stages (Church 1984; Gibbon et al. 1997; Hinton and Meck 1997; Paule et al. 1999; Meck 2001; Buhusi 2003). A variety of theoretical models have been proposed to account for interval timing in the seconds to minutes range and a number of physiological mechanisms for the "internal clock" have been proposed (e.g., Church 1984; Gibbon et al. 1997; Matell and Meck 2000, 2004; Buhusi and Meck 2005; Meck and N'Diaye 2005). Of particular interest is how the clock gets reset at the end of a timed signal. The general assumption has been that the delivery of reinforcement and/or some sort of feedback mechanism contributes to the storage of the remembered time of reinforcement and resets the clock (Gibbon 1977; Meck 1988; Killeen 1994, 2001; Matell and Meck 1999). In particular, the Striatal Beat-Frequency (SBF) model of interval timing proposes a process of writing and rewriting temporal memory, in which the delivery of reinforcement leads to a phasic burst of dopamine release in the striatum from cell bodies in the substantia nigra pars compacta (SNc). This dopamine burst contributes to the long-term potentiation of synaptic connections among medium spiny neurons in the dorsal striatum and the resetting of temporal integration. This "reset" command can be functionally dissociated from the resetting/ synchronization of cortical oscillatory mechanisms that is proposed to occur at signal onset and which may also involve the phasic release of dopamine (Matell and Meck 2004; Voorn et al. 2004; Lustig and Meck 2005; Lustig et al. 2005).

When timing a single temporal criterion within a trial, it is

'Corresponding author.

E-mail meck@psych.duke.edu; fax (919) 660-5798.

Article published online ahead of print. Article and publication date are at http://www.learnmem.org/cgi/doi/10.1101/lm.31506. optimal to have the delivery of reinforcement reset the interval clock. In contrast, when timing a probabilistic sequence of temporal criteria within a trial, it is suboptimal in terms of accurately predicting the next time of reinforcement to reset the clock if only one is being used or to reset all interval clocks with the delivery of each reinforcement if multiple clocks are used. In this case, optimal performance would be to exert "controlled" resetting of the $\operatorname{clock}(\mathrm{s})$. What the neurobiological basis is for this reset command and the degree to which it can be controlled is currently unknown. It has been demonstrated, however, that although the delivery of reinforcement serves as a potent reset command, it isn't universally issued or received. Individual differences have been observed in which rats can selectively reset an interval clock based upon the sequential probabilities of reinforcement availability at different intervals following signal onset (Matell and Meck 1999)

Previous results have shown that adult offspring of pregnant rats fed with 4.5 times the choline in standard rodent chow show enhanced visuospatial memory (e.g., fewer choices to find eight baited arms of 12 total arms in a radial-arm maze-Meck et al. $1988,1989)$. This same prenatal choline supplementation has been shown to facilitate interval timing and temporal memory in young adult rats (Meck and Williams 1997a) and to improve the ability of mature and aged rats to time two signal durations simultaneously (Meck and Williams 1997b). These effects were attributed, in part, to increased precision in the control of the clock and memory processes involved in duration discrimination as a result of long-term changes in cholinergic mechanisms in both cortical and subcortical structures (Blusztajn et al. 1998; Cermak et al. 1998, 1999; Pyapali et al. 1998; Jones III et al. 1999; Montoya et al. 2000; Albright et al. 2003; Meck and Williams 2003). These effects include increases in both muscarinic and nicotinic receptor binding as a function of perinatal choline supplemen- 
tation (Morley and Garner 1986, 1990; Morley and Fleck 1987; Meck et al. 1989; Peng et al. 1997; Morley and Happe 2000). In addition, it has been demonstrated that adult rats exposed prenatally to a brief period of choline supplementation are more sensitive to the clock speed-enhancing effects of nicotine administration (Meck and Williams 1997a). These findings, taken together with the observed beneficial effects of prenatal choline and nicotine on sustained attention and spatial memory (e.g., Levin et al. 1996b; Mohler et al. 2001; Meck and Williams 2003) suggest the possible synergism of prenatal choline and nicotine effects-possibly involving $\alpha 7$ nicotinic acetylcholine receptor (nAChR) modulation of the striatum and pedunculopontine nucleus (see Holt et al. 1999; Kaneko et al. 2000; Marin et al. 2000; Apicella 2002; Mena-Segovia et al. 2004).

Nicotinic cholinergic receptors located in many brain regions are involved with several important aspects of cognition including attention, learning, memory, and interval timing (e.g., Hinton and Meck 1996; Levin et al. 1996a, 1998; Levin and Simon 1998). Of the various nicotinic receptor subtypes, the $\alpha$ and $\beta$ subunits have been of particular interest in terms of distinguishing their associations with different functional systems. One of these subunits, the $\alpha 7 \mathrm{nAChR}$ has been shown to regulate neurotransmitter release in a variety of brain areas, including dopamine release from the SNc and GABA release in the hippocampus (Alkondon et al. 1999; Tsuneki et al. 2000). Both $\alpha 7$ - and non- $\alpha 7$-containing $\mathrm{nACh}$ receptors are present and functional at early stages of brain development (Maggi et al. 2001) and choline is known to be a selective agonist of the $\alpha 7$ nAChR subtype (Papke et al. 1996; Alkondon et al. 1997). On a molecular level, the $\alpha 7 \mathrm{nAChR}$ appears to have a diversity of functions, but it is not known how these receptors interact with prenatal choline and nicotine administration and whether these molecular events translate into phenotypes. In order to investigate the organizational role of the $\alpha 7 \mathrm{nAChR}$ in the clock reset command, we administered choline, nicotine, and methyllycaconitine (a competitive antagonist selective for the $\alpha 7 \mathrm{nAChR}$ ) individually and in combination with rats during prenatal development, and later evaluated their interval timing ability as adults.

Rats were trained using a modified version of the standard peak-interval (PI) procedure called the "Tri-Peak" procedure (Matell and Meck 1999, 2004; Gallistel et al. 2004; MacDonald and Meck 2005). The Tri-Peak procedure is conceptually similar to the PI procedure in which subjects learn to center a window of responding around a criterion time (Church et al. 1994; Rakitin et al. 1998), but there is one major difference. In the Tri-Peak procedure, the onset of a stimulus signals the beginning of a trial as usual. However, there are three response options, each of which is associated with a different temporal criterion in relation to the beginning of the trial, i.e., there is a "short," "medium," and "long" response option for the delivery of reinforcement as illustrated in Figure 1. One may characterize the three peak functions with respect to each response option across probe trials. The TriPeak response function looks tri-modal, with each peak centered on the expected time of reinforcement associated with the response option. The Tri-Peak procedure is useful because it allows one to simultaneously evaluate interval timing in the context of three different time intervals (e.g., 10, 30, and $90 \mathrm{sec}$ ).

In order to appreciate the potential effects of clock resetting within a trial, it is important to understand the sequential probabilities of reinforcement in the Tri-Peak procedure. The major question is: What gets stored in temporal memory when rats reset vs. run their clocks following the delivery of reinforcement at 10 and $30 \mathrm{sec}$ during a trial in which the rat is timing 10-, 30-, and 90-sec durations simultaneously? In the case where the 30sec criterion is being timed, there are two possible clock readings that can enter into temporal memory. If reinforcement occurs at
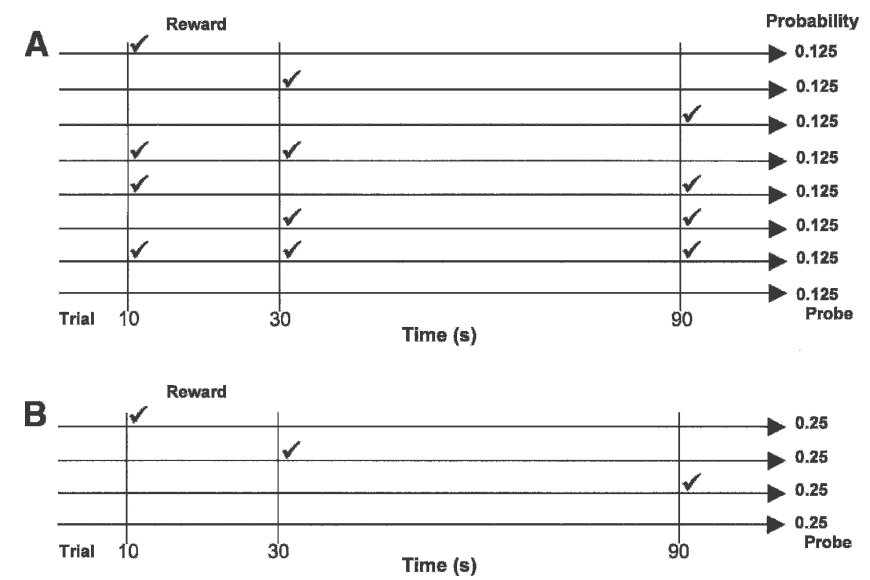

Figure 1. Tri-Peak procedure variants. (A) Multiple rewards $(\checkmark)$ can be earned on an individual trial as a result of making the priming of all combinations of the three fixed-interval $(\mathrm{FI})$ values equally probable, thus allowing for multiple clock resets during a trial (Matell and Meck 1999). $(B)$ A single reward can be earned on an individual trial as a result of the priming of a randomly selected $\mathrm{FI}$ value, thus maximally resetting the internal clock once per trial (Matell et al. 2004; MacDonald and Meck 2005). No reward is primed on probe trials.

$10 \mathrm{sec}$ and the clock is reset, then the clock will report a 20 -sec reading when food is earned at $30 \mathrm{sec}$. If no reinforcement is delivered at $10 \mathrm{sec}$, then the clock will report a 30-sec reading when food is earned at $30 \mathrm{sec}$. Assuming that the 20- and 30-sec clock readings enter memory with equal probability and are given equal weight, then the average storage of this distribution of times of reinforcement would be $25 \mathrm{sec}$. If this type of resetting and "memory mixing" occurs (see Penney et al. 1998, 2000), rats would be expected to center their 30-sec PI functions around 25 sec when reinforcement isn't made available at $10 \mathrm{sec}$, and around $35 \mathrm{sec}$ when reinforcement occurs at $10 \mathrm{sec}$ (due to clock resetting and the subsequent timing of the 25 -sec criterion).

In the case of the 90-sec criterion, there are three possible clock readings that can enter into temporal memory. If reinforcement occurs at $10 \mathrm{sec}$ and the clock is reset, then the clock will report an 80-sec reading when food is earned at $90 \mathrm{sec}$. If reinforcement occurs at $30 \mathrm{sec}$ and the clock is reset, then the clock will report a 60 -sec reading when food is earned at $90 \mathrm{sec}$. If no reinforcement is delivered at either 10 or $30 \mathrm{sec}$, then the clock will report a 90-sec reading when food is earned at $90 \mathrm{sec}$. Assuming that the 80-, 60-, and 90-sec clock readings enter memory with equal probability and are given equal weight, then the average of this distribution of times of reinforcement would be $\sim 77$ sec. In the manner described above, if this type of resetting and memory mixing occurs, rats would be expected to center their 90-sec PI functions around $77 \mathrm{sec}$, when nonreinforcement occurs at both 10 and $30 \mathrm{sec}$, around $87 \mathrm{sec}$ when reinforcement occurs at $10 \mathrm{sec}$, and around $107 \mathrm{sec}$ when reinforcement occurs at $30 \mathrm{sec}$ (due to clock resetting and the subsequent timing of the 77-sec criterion).

These clock resetting and memory mixing effects are the major findings reported by Matell and Meck (1999). The question here is whether any of the prenatal nicotinic drug treatments studied in the present experiment can modify this generic/global resetting mechanism by allowing for selective resetting and thus avoiding the need for mixing different clock readings in temporal memory. If rats were able to selectively reset their clocks, then PI response functions would be expected to be centered around the programmed times of reinforcement (e.g., 10, 30, and $90 \mathrm{sec}$ ) regardless of the within-trial probabilities of reinforcement at each of these criterion durations. 


\section{Results}

\section{Steady-state Tri-Peak response functions}

The mean percent maximum response rate functions combined over all probe trials for the 10-, 30-, and 90-sec criterion durations for combinations of treatment conditions are plotted as a function of signal duration in Figure 2. Peak time, peak rate, and spread measures (mean $\pm \mathrm{SE}$ ) derived from the response-rate functions for each of the treatment conditions are presented separately in Table 1 . A two-way, repeated measures ANOVA for the peak time measure showed a nonsignificant main effect for treatment condition and a significant main effect for criterion duration; $\left[F_{(5,126)}=0.67, P>0.05\right]$ and $\left[F_{(2,126)}=18,733.22\right.$, $P<0.001]$, respectively. In contrast, the treatment $\times$ duration interaction was nonsignificant, $\left[F_{(10,126)}=0.81, P>0.05\right]$. A twoway, repeated measures ANOVA for the peak rate measure showed a significant main effect of criterion duration; $\left[F_{(5,126)}=10.73, P<0.0001\right]$, but nonsignificant effects of treatment condition and the treatment $\times$ duration interaction; $\left[F_{(5,126)}=1.52, P>0.05\right]$ and $\left[F_{(10,126)}=0.18, P>0.05\right]$, respectively. A two-way, repeated measures ANOVA for the spread measure showed significant main effects for both treatment condition and criterion duration $\left[F_{(5,126)}=34.82, P<0.001\right]$ and $\left[F_{(2,126)}=977.25, P<0.001\right]$, respectively. The treatment $\times$ duration interaction was nonsignificant, $\left[F_{(10,126)}=10.52, P>0.05\right]$. These data indicate that although peak times and peak rates differ as a function of the criterion duration (as expected) they are constant across all treatment conditions, while the spreads are significantly smaller across all three criterion durations for the CHO and NIC groups than for the CON, MLA, and $\mathrm{CHO}+\mathrm{NIC}+\mathrm{MLA}$ groups, $P^{\prime} \mathrm{s}<0.05-$ which do not differ from each other. In contrast, the spreads for the $\mathrm{CHO}+$ NIC treatment condition are significantly smaller across all three criterion durations in comparison with all other treatment conditions,
$P^{\prime} \mathrm{s}<0.05$-indicating that rats in this treatment condition exhibited the highest degree of sensitivity to signal duration.

\section{Tri-Peak response measures as a function of the reinforcement status of the preceding criterion duration(s)}

Peak times for the 30-sec criterion duration are plotted as a function of trials in which nonreinforcement (NR) preceded the criterion duration and trials in which reinforcement (R) occurred at $10 \mathrm{sec}$ (Fig. 3, top). A two-way, repeated measures ANOVA with prenatal treatment and reinforcement status as factors showed a nonsignificant main effect of treatment $\left[F_{(5,84)}=0.10, P>0.05\right]$, but a significant main effect of reinforcement status $\left[F_{(1,84)}=269.69, P<0.001\right]$ and a significant treatment $\mathrm{x}$ reinforcement status interaction $\left[F_{(5,84)}=4.91, P<0.005\right]$. Post hoc analysis indicated that $\mathrm{CHO}+\mathrm{NIC}$ rats differed significantly from all other treatment groups. Unlike rats in the other treatment groups, the peak times for $\mathrm{CHO}+\mathrm{NIC}$ rats did not differ between the NR and R10 reinforcement conditions. This result indicates that for rats in the $\mathrm{CHO}+\mathrm{NIC}$ treatment group, reinforcement delivered at an earlier criterion duration (e.g., $10 \mathrm{sec}$ ) did not reset the timing process for later within-trial criterion durations (e.g., $30 \mathrm{sec}$ ).

Peak times for the 90 -sec criterion duration are plotted as a function of trials in which NR preceded the criterion duration and trials in which $\mathrm{R}$ occurred at 10 and/or $30 \mathrm{sec}$ (Fig. 3, bottom). A two-way, repeated measures ANOVA with prenatal treatment and reinforcement status as factors showed a nonsignificant main effect of treatment $\left[F_{(5,126)}=0.42, P>0.05\right]$, but a significant main effect of reinforcement status $\left[F_{(2,126)}=147.06\right.$, $P<0.001]$ and a significant treatment $\times$ reinforcement status interaction $\left[F_{(10,126)}=4.54, P<0.001\right]$. Post hoc analysis indicated that $\mathrm{CHO}+\mathrm{NIC}$ rats differed significantly from all other treatment groups. Unlike rats in the other treatment groups, the peak times for $\mathrm{CHO}+\mathrm{NIC}$ rats did not differ between the NR, R10, and R30 reinforcement conditions $\left[F_{(2,21)}=26.29\right.$, $P>0.05]$. This result indicates that for rats in the $\mathrm{CHO}+\mathrm{NIC}$ treatment group, reinforcement delivered at an earlier criterion duration (e.g., $30 \mathrm{sec}$ ) did not reset the timing process for later withintrial criterion durations (e.g., $90 \mathrm{sec}$ ).

\section{Discussion}

The present results replicate previous findings showing that prenatal choline supplementation facilitates timing and temporal memory (Meck and Williams 1997a,b).

We also replicated the behavioral effects of a version of the Tri-Peak procedure used by Matell and Meck (1999) in which multiple rewards presented at different times on a single trial lead to clock resetting and memory mixing in the majority of control rats. This version (Fig. 1A) of the Tri-Peak procedure is in stark contrast to a different version used in other studies, in which only one of the three possible times of reinforcement is randomly selected for the priming on a single trial (e.g., Gallistel et al. 2004; Matell et al. 2004, 2006; MacDonald and Meck 2005; see Figure 1B). Irre-
Figure 2. Mean maximum percent response rate as a function of signal duration in the Tri-Peak procedure using 10-, 30-, and 90-sec criterion durations for the Control (CON) and prenatal Methyllycaconitine (MLA), Choline (CHO), Nicotine (NIC), Choline + Nicotine $(\mathrm{CHO}+\mathrm{NIC})$, and Choline + Nicotine + Methyllycaconitine $(\mathrm{CHO}+\mathrm{NIC}+\mathrm{MLA})$ treatment conditions. Selected data sets were combined because no significant differences in peak time or spread were observed for these treatment conditions. (CON/MLA*) CON, MLA, and $\mathrm{CHO}+\mathrm{NIC}+\mathrm{MLA}$ conditions combined; (CHO/ $\mathrm{NIC)} \mathrm{CHO}$ and $\mathrm{NIC}$ conditions combined.
Learning \& Memory www.learnmem.org 
Table 1. Steady-state Tri-Peak response functions measures

\begin{tabular}{|c|c|c|c|c|c|c|c|c|c|}
\hline \multirow{2}{*}{$\begin{array}{l}\text { Treatment } \\
\text { Condition }\end{array}$} & \multicolumn{3}{|c|}{$10 \mathrm{sec}$} & \multicolumn{3}{|c|}{$30 \mathrm{sec}$} & \multicolumn{3}{|c|}{$90 \mathrm{sec}$} \\
\hline & Peak Time & Peak Rate & Spread & Peak Time & Peak Rate & Spread & Peak Time & Peak Rate & Spread \\
\hline $\mathrm{CON}$ & $11.63 \pm 0.39$ & $52.0 \pm 4.16$ & $19.38 \pm 1.31$ & $30.81 \pm 0.47$ & $45.88 \pm 3.46$ & $28.63 \pm 0.80$ & $91.69 \pm 0.69$ & $39.13 \pm 3.28$ & $50.88 \pm 1.17$ \\
\hline MLA & $11.31 \pm 0.35$ & $48.5 \pm 4.77$ & $20.50 \pm 0.60$ & $30.19 \pm 0.41$ & $46.75 \pm 4.31$ & $26.75 \pm 1.01$ & $90.75 \pm 0.96$ & $37.25 \pm 3.28$ & $49.63 \pm 1.52$ \\
\hline $\mathrm{CHO}$ & $11.69 \pm 0.55$ & $48.88 \pm 4.87$ & $18.88 \pm 0.74$ & $28.63 \pm 1.54$ & $46.25 \pm 4.43$ & $24.50 \pm 0.78$ & $91.06 \pm 0.83$ & $37.25 \pm 4.17$ & $42.88 \pm 1.23$ \\
\hline NIC & $11.99 \pm 0.57$ & $49.75 \pm 4.22$ & $17.00 \pm 0.57$ & $31.00 \pm 0.73$ & $47.38 \pm 3.37$ & $23.50 \pm 1.17$ & $90.74 \pm 0.88$ & $42.0 \pm 2.35$ & $46.00 \pm 1.34$ \\
\hline $\mathrm{CHO}+\mathrm{NIC}$ & $11.56 \pm 0.46$ & $52.5 \pm 4.94$ & $13.25 \pm 0.31$ & $31.56 \pm 0.54$ & $51.75 \pm 5.15$ & $18.63 \pm 0.71$ & $90.44 \pm 1.01$ & $42.1 \pm 3.37$ & $38.75 \pm 2.72$ \\
\hline $\begin{array}{c}\mathrm{CHO}+\mathrm{NIC}+ \\
\mathrm{MA}\end{array}$ & $11.81 \pm 0.57$ & $46.13 \pm 4.29$ & $22.13 \pm 0.48$ & $30.69 \pm 0.60$ & $38.38 \pm 4.41$ & $28.38 \pm 0.78$ & $91.00 \pm 0.81$ & $35.5 \pm 3.94$ & $50.88 \pm 0.64$ \\
\hline
\end{tabular}

Note: Numbers are means \pm SE. The units for Peak Time and Spread are in seconds and the units for Peak Rate are in responses/minute.

spective of the sequential probabilities of reward, all versions of the Tri-Peak procedure require the operation of a clock reset command that is typically triggered by the delivery of reinforcement. This reset command is similar to the "start" and "stop" commands described in the SBF model for control of an internal clock and are related to dopamine bursts originating from the ventral tegmental area (VTA) and SNc, respectively (see Matell and Meck 2000, 2004; Matell et al. 2003a,b; Teo et al. 2004). This reset command may be restricted to a single signal duration/clock rather than to all signal durations/clocks. Consequently, in order to have "selective" clock resetting as a function of multiple criterion times/reinforcement deliveries, the rat must be able to establish independence among the attention, clock, memory, and decision resources allocated to each temporal criterion. It is this independence that provides evidence for parallel processing of multiple intervals, i.e., it is as if the rat were operating a different clock for each temporal criterion (see Meck and Church 1984; Hinton and Meck 1997; Matell and Meck 1999).

Using an implementation of the Tri-Peak procedure, in

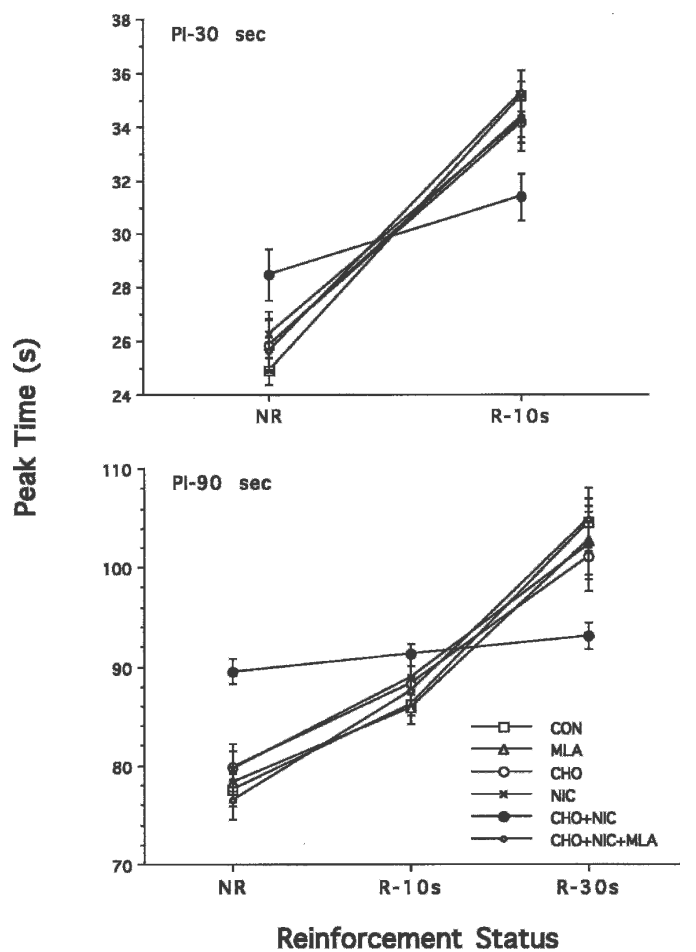

Figure 3. Peak times (mean $\pm \mathrm{SE}$ ) for the 30 -sec peak-interval (PI) criterion (top) and the 90 -sec PI criterion (bottom) as a function of the reinforcement status of the preceding criterion duration(s): nonreinforcement (NR), reinforcement at $10 \mathrm{sec}(\mathrm{R}-10 \mathrm{~s})$, and/or reinforcement at $30 \mathrm{sec}(\mathrm{R}-30 \mathrm{~s})$. which reinforcers were delivered probabilistically at three different criterion times, we demonstrated that rats administered choline or nicotine prenatally exhibit significantly sharper timing functions compared with control rats. These facilitative effects were even more pronounced when coadministering choline and nicotine prenatally as revealed by the highest levels of timing precision for the $\mathrm{CHO}+\mathrm{NIC}$ group when compared with all other treatment groups. Hence, a synergistic effect of combining prenatal choline and nicotine administration was revealed in the present study that was similar in magnitude to the memoryenhancing effects of combining choline and piracetam in aged rats (Bartus et al. 1981; see also, Teather and Wurtman 2005). Furthermore, results based on the reinforcement status of the programmed criterion times $(10,30$, and $90 \mathrm{sec})$ indicated that only the $\mathrm{CHO}+\mathrm{NIC}$-treated rats performed in a manner that allowed for the accurate sequential placement of peak times near the programmed times of reinforcement regardless of the reinforcement status of each criterion. When taking reinforcement status into consideration, all other prenatal treatment groups tended to adopt a reset rule, showing biased peak times for the 30- and 90-sec criteria as was previously described. In summary, the present findings fit into the SBF-timing model (Matell and Meck 2000, 2004; Matell et al. 2003a,b), in that a reset mechanism exists. Furthermore, this reset mechanism seems to be regulated by a central cholinergic system and can determine the accuracy and precision of the temporal memory in rats.

Another important finding in the current study is that when combining prenatal choline and nicotine treatments together, the original facilitative effect of each drug was enhanced. This synergistic effect, however, was eliminated in another group of rats when prenatally coadministered with methyllycaconitine, a competitive and selective antagonist for the $\alpha 7 \mathrm{nAChR}$. Consequently, the current findings may be attributed to organizational changes in the $\alpha 7 \mathrm{nAChR}$, which, when activated by a combination of specific and nonspecific nACh agonists (e.g., choline and nicotine, respectively), can produce interactive and synergistic effects in the control of dopaminergic function in the basal ganglia (Papke et al. 1996; Alkondon et al. 1997; Cao et al. 2005).

It has also been reported that the $\alpha 7 \mathrm{nAChR}$ can regulate the release of dopamine from the SNc to the striatum (Tsuneki et al. 2000). These two brain regions are critical to the normal functioning of an internal clock and have been integrated into neurobiological models of interval timing (Meck 1996; Gibbon et al. 1997). According to the SBF timing model (Matell and Meck 2000, 2004; Matell et al. 2003a,b), bursts of dopamine release from the SNc to the striatum could serve as a signal to both initiate timing and to reset the current clock reading. When a trial begins with the onset of the "to be timed" signal (i.e., a 93-dB tone in the current study), the subjects need to initiate the clock by synchronizing oscillatory processes in the cortex. Later in the trial, when a reward is delivered (e.g., at $10 \mathrm{sec}$ ), the rats can either reset the current clock reading or allow the clock to 
continue to run without interruption. As elaborated above, adopting a reset rule in the current version of the Tri-Peak procedure would result in a memory mixing effect for the 30-sec and 90 -sec reinforcement conditions (i.e., a 25 -sec average value would be remembered as the criterion duration for the 30 -sec condition by mixing 20 - and 30 -sec times of reinforcement, and a 77-sec average value would be remembered as the criterion duration for the 90-sec condition by mixing 60-, 80-, and 90-sec times of reinforcement). This is exactly the behavioral result that was observed for control rats by Matell and Meck (1999) as well as in all of the current groups, with the exception of the $\mathrm{CHO}+\mathrm{NIC}$ treatment group. For those rats that adopted a reset rule, the reinforcement given at $10 \mathrm{sec}$ triggered a reset command, which was triggered again when reinforcement was delivered at $30 \mathrm{sec}$.

In terms of the neurobiological basis for the reset command, our proposal is that the release of a pulse of dopamine from the $\mathrm{SNc}$ to the striatum serves both as an unconditioned stimulus (US) and as a discriminative cue or conditioned stimulus (CS), that predicts the next time of reinforcement to be $\sim 25 \mathrm{sec}$ (or $\sim 77$ sec for the 90-sec condition). This proposal is consistent with the finding that when a CS becomes a reliable predictor for the US, the CS itself acquires the ability to trigger a burst of dopamine release from the mid-brain (Schultz et al. 1997; Schultz 1998). It also fits well with the observation that dopamine neurons report an error in the temporal prediction of reward (Hollerman and Schultz 1998), a finding that is integral to the SBF model of interval timing in terms of providing support for the neuropharmacological basis of the reset command. However, in the case of the $\mathrm{CHO}+$ NIC rats, they clearly did not adopt a reset rule when they encountered reinforcement at 10 and $30 \mathrm{sec}$; instead, they accurately produced peak times centered around the correct criterion times (e.g., 10, 30, and $90 \mathrm{sec}$ ) without showing any evidence of a memory mixing effect. To account for the absence of memory-mixing effect, either they adopted a "run" rule and continued to operate their clock before, during, and after receiving reinforcement at 10 and $30 \mathrm{sec}$, or they had an increased capacity to simultaneously time three different intervals, which exempted them from issuing unnecessary reset commands (see Meck and Williams 1997b). The possible up-regulation of $\alpha 7 \mathrm{nAChR}-$ binding sites induced by prenatal $\mathrm{CHO}+$ NIC supplementation (see Hagino and Lee 1985; Morley and Garner 1986, 1990; Morley and Fleck 1987; Morley and Happe 2000) may allow for the withholding of reset commands directed toward specific corticostriatal circuits that are associated with different temporal criteria (see Bamford et al. 2004; Matell and Meck 2004; Morris et al. 2004). Such selective resetting would allow $\mathrm{CHO}+$ NIC rats to keep their clock(s) running after encountering early reward deliveries in the Tri-Peak procedure. This proposal is reminiscent of the observation that lesions of the frontal cortex prevent rats from timing multiple durations simultaneously, but still allows them to time one interval at a time (Olton et al. 1988). In the present case, the hypothesized up-regulation and/or modification of $\alpha 7 \mathrm{nAChRs}$ allows for further independence in the timing of multiple durations through the selective resetting of corticostriatal circuits.

Numerous studies have reported that nicotine is a potent neuroteratogen that disrupts brain development by stimulating nAChRs that control neural cell replication and differentiationtypically leading to impairments of learning and memory in adulthood (e.g., Sershen et al. 1982; Slotkin et al. 1987a,b; Ribary and Lichtensteiger 1989; Sorenson et al. 1991; Seidler et al. 1992; Yanai et al. 1992; Vaglenova et al. 2004). Virtually all of these previous studies utilized considerably higher doses of maternal nicotine treatment (e.g., $6 \mathrm{mg} / \mathrm{kg} /$ day) compared with the $2 \mathrm{mg} /$ $\mathrm{kg} /$ day dose used in the present study, which is more comparable to studies reporting beneficial effects of prenatal nicotine administration on adult cognition (e.g., Cutler et al. 1996; Levin et al. 1996b; see also Zhou and Suszkiw 2004). Interestingly, Slotkin et al. (2005) recently reported that prenatal choline administration can ameliorate some of the deleterious effects of high-level prenatal nicotine exposure on brain bio-markers in rhesus monkeys.

The negligible effect of administering MLA prenatally and its ability to block the cognitive-enhancing effects of prenatal choline + nicotine administration observed in the present study suggest that some of the functions of the $\alpha 7 \mathrm{nAChR}$ are unidirectional rather than bidirectional. For example, in a related series of experiments, the absence of the $\alpha 7$ nAChR in Acra7deficient mice did not impair basic learning and memory processes as indexed by performance in tests of Pavlovianconditioned fear, spatial learning in the Morris water maze, open field and exploratory activity, acoustic startle, and prepulse inhibition of the acoustic startle response (Paylor et al. 1998). In contrast, stimulation of the $\alpha 7$ nAChR with the novel agonist AR-R17779 improved learning and memory in control rats and rats with fimbria-fornix transections tested on an 8-arm radial maze (Levin et al. 1999).

Previous research has documented the roles of muscarinic acetylcholine receptor agonists and antagonists as well as the effects of damage to the cholinergic connections between the medial septal area and hippocampus and the nucleus basalis and frontal cortex on interval timing and temporal memory (Meck 1996, 2002a). The general observation has been that these manipulations can alter the content of temporal memory by modulating the speed of transfer of clock readings into temporal memory. Thus, the physical durations of events can be misrepresented in memory as being proportionally shorter or longer depending upon the effective levels of acetylcholine in the hippocampus and frontal cortex (e.g., Meck 1983, 1996, 2002a,b; Meck and Church 1987a,b; Meck et al. 1984, 1987; Olton et al. 1988). The present results, however, are the first to document a specific role for nicotinic mechanisms in clock resetting and temporal memory.

In conclusion, a small but significant enhancement of temporal precision was obtained by providing prenatal choline or nicotine supplementation to rats later trained as adults in the Tri-Peak procedure. Furthermore, the co-administration of prenatal choline and nicotine was observed to produce a synergistic effect, such that rats in the $\mathrm{CHO}+$ NIC treatment group showed the highest level of temporal precision with regard to all three criterion durations (e.g., 10, 30, and $90 \mathrm{sec}$ ). In addition, the ability to selectively control the clock's "reset" mechanism for each of the three durations was found to reliably occur only for rats in the $\mathrm{CHO}+$ NIC treatment group. This degree of behavioral independence among the different times of reward within a trial suggests that these rats were able to time each of the durations using a different clock. Interestingly, the cognitive-enhancing effects observed in the $\mathrm{CHO}+\mathrm{NIC}$ rats, both increased precision and selective resetting, were completely abolished by prenatally coadministering MLA, a selective $\alpha 7 \mathrm{nAChR}$ antagonist. The observation that MLA co-administration blocked the cognitiveenhancing effects of prenatal choline and/or nicotine administration suggests that these substances produce their facilitative effects through the regulation of $\alpha 7 \mathrm{nAChRs}$ in the developing brain and that these effects on brain and behavior are long lasting (see Meck and Williams 2003).

\section{Materials and Methods}

\section{Rats}

Thirty-six litters of timed-pregnant Sprague-Dawley Crl: $\mathrm{CD}(\mathrm{SD}) \mathrm{BR}-\mathrm{CD}$ strain rats (Charles River Laboratories) were 
used to generate six groups of prenatally treated male rats $(n=48)$ : Control $(\mathrm{CON})$, Choline $(\mathrm{CHO})$, Nicotine (NIC), Choline + Nicotine $(\mathrm{CHO}+\mathrm{NIC})$, Methyllycaconitine (MLA), and Choline + Nicotine + Methyllycaconitine $(\mathrm{CHO}+\mathrm{NIC}+\mathrm{MLA})$. Upon arrival at our laboratory, the pregnant dams were given a modified AIN-76A purified diet (Dyets Inc.) with $1.1 \mathrm{~g} / \mathrm{kg}$ choline chloride substituted for choline bitartrate and water ad libitum.

Prenatal nicotine and methyllycaconitine (MLA) treatments were given by anesthetizing the dams with ether and subcutaneously implanting Alzet osmotic minipumps (Model 2ML2-Alza) between the scapulae. Twelve dams were given NIC-containing pumps, six were given MLA-containing pumps, six were given NIC + MLA-containing pumps, and 12 were given salinecontaining pumps. Nicotine ditartrate (Sigma) was administered in a dose of $2 \mathrm{mg} / \mathrm{kg} /$ day and methyllycaconitine (Sigma) was administered in a dose of $20 \mathrm{mg} / \mathrm{kg} /$ day. The dose refers to the weight of the base. The dams were implanted on ED 9. According to information supplied by the manufacturer, the 2ML2 minipumps deliver $4.84 \mu \mathrm{L} /$ hour with a standard deviation of $5.2 \%$ for $\sim 16.7 \mathrm{~d}$. (See Levin et al. 1996b for additional details concerning the use of osmotic minipumps for prenatal drug administration.)

Half of the dams in the NIC and saline osmotic minipump conditions, as well as all of the dams in the NIC + MLA condition, were also given prenatal choline supplementation in order to produce the $\mathrm{CHO}, \mathrm{CHO}+\mathrm{NIC}$, and $\mathrm{CHO}+\mathrm{NIC}+$ MLA treatment groups. Prenatal choline treatment was given by adding a 25-mM solution during ED 11-17 via saccharine-sweetened drinking water $(50 \mathrm{mM})$. Based on water consumption, the average choline dose for supplementation of the dams during gestation was $250 \mathrm{mg} / \mathrm{kg} / \mathrm{day}$. Dams of the offspring to later be included in the NIC and CON treatment groups received saccharine-sweetened drinking water with no added choline. There were no significant differences in the amount of diet or water consumed by the dams in the different treatment groups, P's $<0.05$. (See Jones III et al. 1999 for additional details concerning prenatal choline supplementation.)

At birth, all pups were randomly divided among untreated foster mothers (12 pups/litter) such that each dam raised two male pups from each condition. All pups were weaned at PD 25 , after which rats were housed in pairs and given free access to the modified AIN-76A diet and water.

Behavioral training began at $\sim 4$ mo of age. One week prior to the start of training, the rats were placed on a 24 -h food deprivation schedule, during which they were fed $\sim 12 \mathrm{~g} /$ day of the purified diet (AIN76A) during a single daily feeding in order to maintain them at $80 \%-85 \%$ of their free-feeding weights throughout the experiment. A 12-h light/12-h dark cycle was maintained in the vivarium with fluorescent lights on from 8:00 to 20:00 EST.

\section{Apparatus}

All experimental data were collected in 12 operant-conditioning chambers constructed of an aluminum front wall and three Plexiglas slide walls and ceiling. The floor was constructed of stainless steel parallel bars with a drop tray underneath. Three response levers were evenly spaced across the front wall of the chamber, $2.5 \mathrm{~cm}$ above the grid floor. A pellet dispenser delivered $45-\mathrm{mg}$ food pellets (Noyes Precision, Formula A; P.J. Noyes) to a food cup located in the middle of the front wall and below the levers. A $2.5-\mathrm{cm}$ Sonalert (P.R. Mallory \& Co.), calibrated to $93 \mathrm{~dB}$ with respect to background, was mounted on the front wall of the chamber above the food cup. A $6 \mathrm{~W}$ houselight was located on the ceiling and was illuminated throughout the session. Each operant conditioning chamber was housed inside a light and soundinsulated box, and was equipped with a ventilation fan and an eyepiece viewer for observation. An IBM-PC compatible computer attached to an electronic interface was used to control the experimental equipment and record the behavioral responses.
}

\section{Behavioral procedures \\ Pretraining (sessions 1-6)}

All rats received six sessions of combined magazine and lever training. During these sessions, a food pellet was delivered once a minute for $60 \mathrm{~min}$. In addition, one of the side response levers was primed until 15 responses were made on that lever, at which point the middle response lever was primed for 15 responses, and finally, the other side lever was primed for 15 responses. During the time that the side levers were primed, the primed lever was retracted for a 1-sec period $2 \mathrm{sec}$ before free-pellet delivery. The direction in which the levers were primed (e.g., left lever, middle lever, right lever) was based on the eventual direction of the "short," "medium," and "long" duration-associated responses in the final procedure (see below). This procedure was repeated until the rat pressed each lever 30 times or $60 \mathrm{~min}$ had passed, thus ending the session. The houselight illuminated the chamber upon completion of the session.

\section{FI training in increasing-duration order (sessions 7-12)}

Sessions began with the illumination of the houselight and onset of a 93-dB tone. A 10-sec FI was scheduled upon either the right or left response lever (counterbalanced across rats). The first response after $10 \mathrm{sec}$ was reinforced with a $45-\mathrm{mg}$ Noyes pellet and the sound stimulus was turned off. After a 2-sec delay, which is unique to this training phase only, the sound stimulus was turned back on and a 30-sec FI schedule was imposed upon the middle lever. Following reinforcement of this lever press, the sound stimulus was again turned off for $2 \mathrm{sec}$. The sound stimulus was then turned on again and a 90-sec FI was scheduled upon the remaining side lever. After reinforcement was earned for this lever, the sound was turned off and a random intertrial interval (ITI-55-sec mean, range 40-70 sec) began. This procedure was repeated for $95 \mathrm{~min}$. The short within-trial break between the increasing duration FIs were used to "move" the rat from one side of the operant chamber to the other during the three FI trials. For each FI duration, the trial would self-terminate if the rat did not make a response after the criterion time and before three times the criterion time plus a random $0 \%-20 \%$ of the $3 \times$ criterion time (e.g., a 30-sec trial lasted anywhere from 90 to $108 \mathrm{sec}$ ).

\section{FI training in random order (sessions 13-18)}

Sessions were identical to those described above, with the exception that on any particular trial, the FI durations that would be primed were randomly selected, and the full 55-sec ITI was instituted after every trial. In these trials, no indication was given to the rat as to which FI values (e.g., 10, 30, or $90 \mathrm{sec}$ ) would be selected on any particular trial and all combinations were equally probable (e.g., one, two, or three different FIs could be primed on a single trial). As a consequence, rats would begin each trial by orienting themselves in front of the "short" lever. If responding on this lever did not pay off, the rat would then switch to the "middle" lever. If reinforcement failed to be primed on this lever, the rat would switch to the "long" lever, for which responding would be reinforced following the 90 -sec criterion. All trial types were selected with equal probability. (Fig. 3)

Tri-Peak training sessions (sessions 19-50)

These sessions were identical to the FIs in random order, with the exception that a nonreinforced "probe" trial was added to the trial types randomly selected for each trial. These nonreinforced probe trials lasted for the same length of time as the selfterminating 90-sec FI trials (e.g., 270-330 sec).

\section{Data analysis}

For each rat, responses recorded for each of the three levers/ criterion durations were averaged over the last 10 sessions of steady-state training and normalized as a function of each lever's maximal response rate. Tri-Peak functions for each group were obtained by calculating the mean response function for each treatment condition and then renormalizing the mean function as a percent of the maximum response. Statistical measures of the Tri-Peak functions were derived by fitting each rat's data with a Gaussian curve + linear ramp function, with the mean of the 
fitted Gaussian function being used as a measure of the peak time, and the width of the normalized Gaussian function at the 60th percentile serving as a measure of spread. ANOVA's were conducted on these Tri-Peak measures, conditional upon the temporal sequence of reinforcement as a function of treatment condition. Post hoc comparisons were conducted by using Fisher's Protected LSD tests.

\section{Acknowledgments}

This work was financially supported by grants from the National Institute of Aging (AG09525).

\section{References}

Albright, C.D., Siwek, D.F., Craciunescu, C.N., Mar, M.H., Kowall, N.W., Williams, C.L., and Zeisel, S.H. 2003. Choline availability during embryonic development alters the localization of calretinin in developing and aging mouse hippocampus. Nutr. Neurosci. 6: $129-134$.

Alkondon, M., Pereira, E.F.R., Cortes, W.S., Maelicke, A., and Albuquerque, E.X. 1997. Choline is a selective agonist of $\alpha 7$ nicotinic acetylcholine receptors in the rat brain neurons. Eur. J. Neurosci. 9: 2734-2742.

Alkondon, M., Pereira, E.F.R., Eisenberg, H.M., and Albuquerque, E.X 1999. Choline and selective antagonists identify two subtypes of nicotinic acetylcholine receptors that modulate GABA release from CA1 interneurons in rat hippocampal slices. J. Neurosci. 19: 2693-2705.

Apicella, P. 2002. Tonically active neurons in the primate striatum and their role in the processing of information about motivationally relevant events. Eur. J. Neurosci. 16: 2017-2026.

Bamford, N.S., Zhang, H., Schmitz, Y., Wu, N.-P., Cepeda, C., Levine, M.S., Schmauss, C., Zakharrenko, S.S., Zablow, L., and Sulzer, D. 2004. Heterosynaptic dopamine neurotransmission selects sets of corticostriatal terminals. Neuron 42: 653-663.

Bartus, R.T., Dean III, R.L., Sherman, K.A., Friedman, E., and Beer, B. 1981. Profound effects of combining choline and piracetam on memory enhancement and cholinergic function in aged rats. Neurobiol. Aging 2: 105-111.

Blusztajn, J.K., Cermak, J.M., Holler, T., and Jackson, D.A. 1998. Imprinting of hippocampal metabolism of choline by its availability during gestation: Implications for cholinergic neurotransmission. $J$. Physiol. 92: 199-203.

Buhusi, C.V. 2003. Dopaminergic mechanisms of interval timing and attention. In Functional and neural mechanisms of interval timing (ed. W.H. Meck), pp. 317-338. CRC Press, Boca Raton, FL.

Buhusi, C.V. and Meck, W.H. 2005. What makes us tick? Functional and neural mechanisms of interval timing. Nat. Rev. Neurosci. 6: $755-765$.

Cao, Y.-J., Surowy, C.S., and Puttfarcken, P.S. 2005. Different nicotinic acetylcholine receptor subtypes mediating striatal and prefrontal cortical $\left[{ }^{3} \mathrm{H}\right]$ dopamine release. Neuropharmacology 48: 72-79.

Cermak, J.M., Holler, T., Jackson, D.J., and Blusztajn, J.K. 1998. Prenatal availability of choline modifies development of the hippocampal cholinergic system. FASEB J. 12: 349-357.

Cermak, J.M., Blusztajn, J.K., Meck, W.H., Williams, C.L., Fitzgerald, C., Rosene, D.L., and Loy, R. 1999. Prenatal availability of choline alters the development of acetylcholinesterase in rat hippocampus. Dev. Neurosci. 21: 94-104.

Church, R.M. 1984. Properties of the internal clock, In Annals of the New York Academy of Sciences: Timing and time perception (eds. J. Gibbon and L.G. Allan), pp. 566-582, New York Academy of Sciences, New York.

Church, R.M., Meck, W.H., and Gibbon, J. 1994. Application of scalar timing theory to individual trials. J. Exp. Psychol. Anim. Behav. Process. 20: $135-155$.

Cutler, A.R., Wilkerson, A.E., Gingras, J.L., and Levin, E.D. 1996. Prenatal cocaine and/or nicotine exposure in rats: Preliminary findings on long-term cognitive outcome and genital development at birth. Neurotoxicol. Teratol. 18: 635-643.

Gallistel, C.R., King, A., and McDonald, R. 2004. Sources of variability and systematic error in mouse timing behavior. J. Exp. Psychol. Anim. Behav. Process. 30: 3-16.

Gibbon, J. 1977. Scalar expectancy and Webers law in animal timing. Psychol. Rev. 84: 279-325.

Gibbon, J., Malapani, C., Dale, C.L., and Gallistel, C.R. 1997. Toward a neurobiology of temporal cognition: Advances and challenges. Curr Opin. Neurobiol. 7: 170-184.

Hagino, N. and Lee, J.W. 1985. Effect of maternal nicotine on the development of sites for $\left[{ }^{3} \mathrm{H}\right]$ nicotine binding in the fetal brain. Int. J. Dev. Neurosci. 3: 567-571.
Hinton, S.C. and Meck, W.H. 1996. Increasing the speed of an internal clock: The effects of nicotine on interval timing. Drug Dev. Res. 38: 204-211.

. 1997. How time flies: Functional and neural mechanisms of interval timing. In Time and behaviour: Psychological and neurobiological analyses (eds. C.M. Bradshaw and E. Szabadi), pp. 409-457, Elsevier, New York.

Hollerman, J.R. and Schultz, W. 1998. Dopamine neurons report an error in the temporal prediction of reward during learning. Nat. Neurosci. 1: 304-309.

Holt, D.J., Herman, M.M., Hyde, T.M., Kleinman, J.E., Sinton, C.M., German, D.C., Hersh, L.B., Graybiel, A.M., and Saper, C.B. 1999. Evidence for a deficit in cholinergic interneurons in the striatum in schizophrenia. Neuroscience 94: 21-31.

Jones III, J.P., Meck, W.H., Williams, C.L., Wilson, W.A., and Swartzwelder, S.H. 1999. Choline availability to the developing rat fetus alters adult hippocampal long-term potentiation. Brain Res. Dev. Brain Res. 118: 159-167.

Kaneko, S., Hikida, T., Watanabe, D., Ichinose, H., Nagatsu, T., Kreitman, R.J., Pastan, I., and Nakanishi, S. 2000. Synaptic integration mediated by striatal cholinergic interneurons in basal ganglia function. Science 289: 633-637.

Killeen, P.R. 1994. Mathematical principles of reinforcement: Based on the correlation of behaviour with incentives in short-term memory. Behav. Brain Sci. 17: 105-172.

. 2001. Writing and overwriting short-term memory. Psychon. Bull. Rev. 8: 18-43.

Levin, E.D. and Simon, B.B. 1998. Nicotinic acetylcholine involvement in cognitive function in animals. Psychopharmacology 138: 217-230.

Levin, E.D., Conners, C.K., Sparrow, E., Hinton, S.C., Erhardt, D., Meck, W.H., Rose, J.E., and March, J. 1996a. Nicotine effects on adults with attention-deficit/hyperactivity disorder. Psychopharmacology 123: $55-63$.

Levin, E.D., Wilkerson, A., Jones, J.P., Christopher, N.C., and Briggs, S.J. 1996b. Prenatal nicotine effects on memory in rats: Pharmacological and behavioral challenges. Brain Res. Dev. Brain Res. 97: 207-215.

Levin, E.D., Conners, C.K., Silva, D., Hinton, S.C., Meck, W.H., March, J., and Rose, J.E. 1998. Transdermal nicotine effects on attention. Psychopharmacology 140: 135-141.

Levin, E.D., Bettegowda, C., Blosser, J., and Gordon, J. 1999. AR-R17779, an $\alpha 7$ nicotinic agonist, improves learning and memory in rats. Behav. Pharmacol. 10: 675-680.

Lustig, C. and Meck, W.H. 2005. Chronic treatment with haloperidol induces working memory deficits in feedback effects of interval timing. Brain Cogn. 58: 9-16.

Lustig, C., Matell, M.S., and Meck, W.H. 2005. Not "just" a coincidence: Frontal-striatal synchronization in working memory and interval timing. Memory 13: 441-448.

MacDonald, C.J. and Meck, W.H. 2005. Differential effects of clozapine and haloperidol on interval timing in the supraseconds range. Psychopharmacology 182: 232-244.

Maggi, L., Sher, E., and Cherubini, E. 2001. Regulation of GABA release by nicotinic acetylcholine receptors in the neonatal rat hippocampus. J. Physiol. 536: 89-100.

Marin, O., Anderson, S.A., and Rubenstein, J.L.R. 2000. Origin and molecular specification of striatal interneurons. J. Neurosci. 20: 6063-6076.

Matell, M.S. and Meck, W.H. 1999. Reinforcement-induced within-trial resetting of an internal clock. Behav. Processes 45: 159-171.

. 2000. Neuropsychological mechanisms of interval timing behaviour. Bioessays 22: 94-103.

. 2004. Cortico-striatal circuits and interval timing: Coincidence-detection of oscillatory processes. Brain Res. Cogn. Brain Res. 21: 139-170.

Matell, M.S., Meck, W.H., and Nicolelis, M.A.L. 2003a. Integration of behavior and timing: Anatomically separate systems or distributed processing? In Functional and neural mechanisms of interval timing. (ed. W.H. Meck), (pp. 371-391). CRC Press, Boca Raton, FL.

- 2003b. Interval timing and the encoding of signal duration by ensembles of cortical and striatal neurons. Behav. Neurosci. 117: 760-773.

Matell, M.S., King, G.R., and Meck, W.H. 2004. Differential adjustment of interval timing by the chronic administation of intermittent or continuous cocaine. Behav. Neurosci. 118: 150-156.

Matell, M.S., Bateson, M., and Meck, W.H. 2006. Single-trials analyses demonstrate that increases in clock speed contribute to the methamphetamine-reduced horizontal shifts in peak-interval timing functions. Psychopharmacology (in press).

Meck, W.H. 1983. Selective adjustment of the speed of internal clock and memory storage processes. J. Exp. Psychol. Anim. Behav. Process. 9: $171-201$.

. 1988. Internal clock and reward pathways share physiologically 
similar information-processing stages. In Quantitative analyses of behavior: Biological determinants of reinforcement (eds. M.L. Commons, et al.), Vol. 7, pp. 121-138. Erlbaum, Hillsdale, NJ.

-. 1996. Neuropharmacology of timing and time perception. Brain Res. Cogn. Brain Res. 3: 227-242.

. 2001. Interval timing and genomics: What makes mutant mice tick? Int. J. Comp. Psychol. 14: 211-231.

2002a. Choline uptake in the frontal cortex is proportional to the absolute error of a temporal memory translation constant in mature and aged rats. Learn. Motiv. 33: 88-104.

. 2002b. Distortions in the content of temporal memory: Neurobiological correlates. In Animal cognition and sequential behavior: Behavioral, biological, and computational perspectives (eds. S.B. Fountain, et al.), pp. 175-200. Kluwer Academic Press, Boston, MA.

Meck, W.H. and Church, R.M. 1984. Simultaneous temporal processing. J. Exp. Psychol. Anim. Behav. Process. 10: 1-29.

. 1987a. Cholinergic modulation of the content of temporal memory. Behav. Neurosci. 101: 457-464.

. 1987b. Nutrients that modify the speed of internal clock and memory storage processes. Behav. Neurosci. 101: 465-475.

Meck, W.H. and N'Diaye, K. 2005. Un modèle neurobiologique de la perception et de l'estimation du temps. Psychologie Francaise 50: $47-63$.

Meck, W.H. and Williams, C.L. 1997a. Characterization of the facilitative effects of perinatal choline supplementation on timing and temporal memory. Neuroreport 8: 2831-2835.

- $1997 \mathrm{~b}$. Simultaneous temporal processing is sensitive to prenatal choline availability in mature and aged rats. Neuroreport 8: $3045-3051$.

. 2003. Metabolic imprinting of choline by its availability during gestation: Implications for memory and attentional processing across the lifespan. Neurosci. Biobehav. Rev. 27: 385-399.

Meck, W.H., Church, R.M., and Olton, D.S. 1984. Hippocampus, time, and memory. Behav. Neurosci. 98: 3-22.

Meck, W.H., Church, R.M., Wenk, G.L., and Olton, D.S. 1987. Nucleus basalis magnocellularis and medial septal area lesions differentially impair temporal memory. J. Neurosci. 7: 3505-3511.

Meck, W.H., Smith, R.A., and Williams, C.L. 1988. Pre- and postnatal choline supplementation produces long-term facilitation of spatial memory. Dev. Psychobiol. 21: 339-353.

. 1989. Organizational changes in cholinergic activity and enhanced visuospatial memory as a function of choline administered prenatally or postnatally or both. Behav. Neurosci. 103: $118-146$.

Mena-Segovia, J., Bolam, J.P., and Magill, P.J. 2004. Pedunculopontine nucleus and basal ganglia: Distant relatives or part of the same family? Trends Neurosci. 27: 585-588.

Mohler, E.G., Meck, W.H., and Williams, C.L. 2001. Sustained attention in adult mice is modulated by prenatal choline availability. Int. J. Comp. Psychol. 14: 136-150.

Montoya, D.A.C., White, A.M., Williams, C.L., Blusztajn, J.K., Meck, W.H., and Swartzwelder, H.S. 2000. Prenatal choline exposure alters hippocampal responsiveness to cholinergic stimulation in adulthood. Brain Res. Dev. Brain Res. 123: 25-32.

Morley, B.J. and Fleck, D.L. 1987. A time course and dose-response study of the regulation of brain nicotinic receptors by dietary choline. Brain Res. 421: 21-29.

Morley, B.J. and Garner, L.L. 1986. Increases in the concentration of brain $\alpha$-bungarotoxin binding sites induced by dietary choline are age-dependent. Brain Res. 378: 315-319.

. 1990. AF64A depletes hippocampal high-affinity choline uptake but does not alter the density of $\alpha$-bungarotoxin binding sites or modify the effect of exogenous choline. Brain Res. 519: 1-5.

Morley, B.J. and Happe, H.K. 2000. Cholinergic receptors: Dual roles in transduction and plasticity. Hear. Res. 147: 104-112.

Morris, G., Arkadir, D., Nevet, A., Vaadia, E., and Bergman, H. 2004. Coincident but distinct messages of midbrain dopamine and striatal tonically active neurons. Neuron 43: 133-143.

Olton, D.S., Wenk, G.L., Church, R.M., and Meck, W.H. 1988. Attention and the frontal cortex as examined by simultaneous temporal processing. Neuropsychologia 26: 307-318.

Papke, R.L., Bencherif, M., and Lippiello, P. 1996. An evaluation of neuronal nicotinic acetylcholine receptor activation by quaternary nitrogen compounds indicates that choline is selective for the $\alpha 7$ subtype. Neurosci. Lett. 213: 201-204.

Paule, M.G., Meck, W.H., McMillan, D.E., Bateson, M., Popke, E.J., Chelonis, J.J., and Hinton, S.C. 1999. The use of timing behaviors in animals and humans to detect drug and/or toxicant effects. Neurotoxicol. Teratol. 21: 491-502.

Paylor, R., Nguyen, M., Crawley, J.N., Patrick, J., Beaudet, A., and Orr-Urtreger, A. 1998. $\alpha 7$ nicotinic receptor subunits are not necessary for hippocampal-dependent learning or sensorimotor gating: A behavioral characterization of Acra7-deficient mice. Learn. Mem. 5: 302-316.

Peng, X., Gerzanich, V., Anand, R., Wang, F., and Lindstrom, J. 1997. Chronic nicotine treatment up-regulates $\alpha 3$ and $\alpha 7$ acetylcholine receptor subtypes expressed by the human neuroblastoma cell line SH-SY5Y. Mol. Pharmacol. 51: 776-784.

Penney, T.B., Allan, L.G., Meck, W.H., and Gibbon, J. 1998. Memory mixing in duration bisection. In Timing of behavior: Neural, psychological and computational perspectives. (eds. D.A. Rosenbaum and C.E. Collyer), pp.165-193. MIT Press, Cambridge, MA.

Penney, T.B., Gibbon, J., and Meck, W.H. 2000. Differential effects of auditory and visual signals on clock speed and temporal memory. $J$. Exp. Psychol. Hum. Percept. Perform. 26: 1770-1787.

Pyapali, G.K., Turner, D.A., Williams, C.L., Meck, W.H., and Swartzwelder, H.S. 1998. Prenatal dietary choline supplementation decreases threshold for induction of long-term potentiation in young adult rats. J. Neurophysiol. 79: 1790-1796.

Rakitin, B.C., Gibbon, J., Penney, T.B., Malapani, C., Hinton, S.C., and Meck, W.H. 1998. Scalar expectancy theory and peak-interval timing in humans. J. Exp. Psychol. Anim. Behav. Process. 24: 15-33.

Ribary, U. and Lichtensteiger, W. 1989. Effects of acute and chronic prenatal nicotine treatment on central catecholamine systems of male and female rat fetuses and offspring. J. Pharmacol. Exp. Ther. 248: 786-792.

Schultz, W. 1998. Predictive reward signal of dopamine neurons. J. Neurophysiol. 80: 1-27.

Schultz, W., Dayan, P., and Montague, R.P. 1997. A neural substrate of prediction and reward. Science 275: 1593-1599.

Seidler, F.J., Levin, E.D., Lappi, S.E., and Slotkin, T.A. 1992. Fetal nicotine exposure ablates the ability of postnatal nicotine challenge to release norepinephrine from rat brain regions. Brain Res. Dev. Brain Res. 69: 288-291.

Sershen, H., Reith, M.E.A., Banay-Schwartz, M., and Lajtha, A. 1982. Effects of prenatal administration of nicotine on amino acid pools protein metabolism and nicotine binding in the brain. Neurochem. Res. 7: 1515-1522.

Slotkin, T.A., Orband-Miller, L., and Queen, K.L. 1987a. Development of $\left[{ }^{3} \mathrm{H}\right]$ nicotine binding sites in brain regions of rats exposed to nicotine prenatally via maternal injections or infusions. J. Pharmacol. Exp. Ther. 242: 232-237.

Slotkin, T.A., Orband-Miller, L., Queen, K.L., Whitmore, W.L., and Seidler, F.J. 1987b. Effects of prenatal nicotine exposure on biochemical development of rat brain regions: Maternal drug infusions via osmotic minipumps. J. Pharmacol. Exp. Ther. 240: 602-611.

Slotkin, T.A., Seidler, F.J., Qiao, D., Aldridge, J.E., Tate, C.A., Cousins, M.M., Proskocil, B.J., Sekhon, H.S., Clark, J.A., Lupo, S.L., et al. 2005 Effects of prenatal nicotine exposure on primate brain development and attempted amelioration with supplemental choline or vitamin C: Neurotransmitter receptors, cell signaling and cell development biomarkers in fetal brain regions of rhesus monkeys. Neuropsychopharmacology 30: 129-144

Sorenson, C.A., Raskin, L.A., and Suh, Y. 1991. The effects of prenatal nicotine on radial-arm maze performance in rats. Pharmacol. Biochem. Behav. 40: 991-993.

Teather, L.A. and Wurtman, R.J. 2005. Dietary CDP-choline supplementation prevents memory impairment caused by impoverished environmental conditions in rats. Learn. Mem. 12: $39-43$.

Teo, M.Y., van Wyk, M., Lin, J., and Lipski, J. 2004. Differential effects of nicotine on the activity of substantia nigra and ventral tegmental area dopaminergic neurons in vitro. Acta Neurobiol. Exp. (Wars) 64: $119-130$.

Tsuneki, H., Klink, R., Lena, C., Korn, H., and Changeux, J.-P. 2000. Calcium mobilization elicited by two types of nicotinic acetylcholine receptors in mouse substantia nigra pars compacta. Eur. J. Neurosci. 12: 2475-2485.

Vaglenova, J., Birru, S., Pandiella, N.M., and Breese, C.R. 2004. An assessment of the long-term developmental and behavioral teratogenicity of prenatal nicotine exposure. Behav. Brain Res. 150: $159-170$.

Voorn, P., Vanderschuren, L.J.M.J., Groenewegen, H.J., Robbins, T.W., and Pennartz, C.M.A. 2004. Putting a spin on the dorsal-ventral divide of the striatum. Trends Neurosci. 27: 468-474.

Yanai, J., Pick, C.G., Rogel-Fuchs, Y., and Zahalka, E.A. 1992. Alterations in hippocampal cholinergic receptors and hippocampal behaviors after early exposure to nicotine. Brain Res. Bull. 29: 363-368.

Zhou, M. and Suszkiw, J.B. 2004. Nicotine attenuates spatial learning deficits induced in the rat by perinatal lead exposure. Brain Res. 999: 142-147.

Received July 13, 2005; accepted in revised form December 6, 2005.

\section{Learning \& Memory}




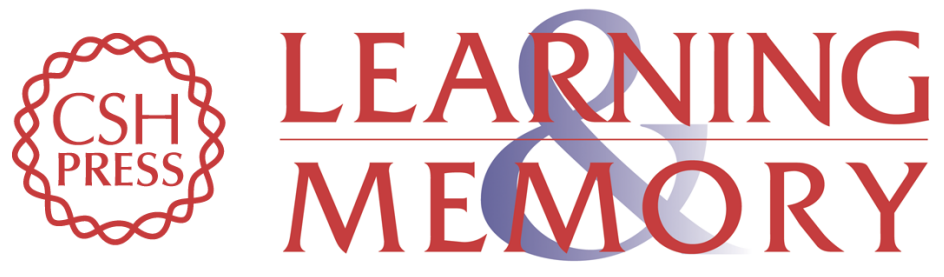

\section{$\alpha 7$ Nicotinic acetylcholine receptors and temporal memory: Synergistic effects of combining prenatal choline and nicotine on reinforcement-induced resetting of an interval clock}

Ruey-Kuang Cheng, Warren H. Meck and Christina L. Williams

Learn. Mem. 2006, 13:

Access the most recent version at doi:10.1101/lm.31506

References This article cites 86 articles, 11 of which can be accessed free at: http://learnmem.cshlp.org/content/13/2/127.full.html\#ref-list-1

License

Email Alerting

Receive free email alerts when new articles cite this article - sign up in the box at the Service top right corner of the article or click here. 